\title{
In vitro Study of the Effect of Internal Relief Space on the Color of Ceramic Laminate Veneer
}

\author{
Abd El Azeem Mostafa ${ }^{1 *}$, Cherif A. Mohsen ${ }^{2}$ \\ ${ }^{1}$ Department of Fixed Prosthodontics, Faculty of Dentistry, South Valley University, Qena, Egypt; ${ }^{2}$ Department of Fixed \\ Prosthodontics, Faculty of Dentistry, Minia University, Minia, Egypt
}

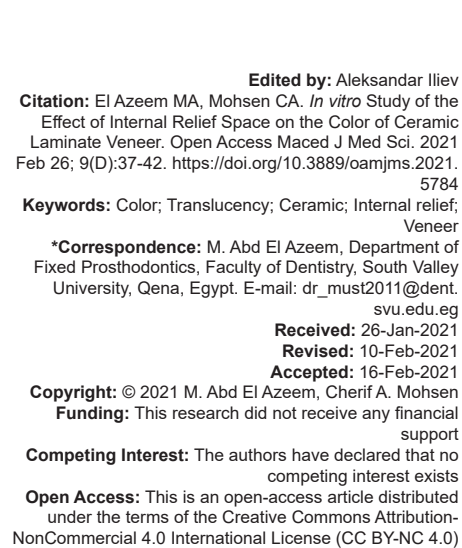

\section{Introduction}

In modern esthetic dentistry, ceramic laminate veneer restoring is considered one of the most conservative solutions for many esthetic complications, as minimal teeth malformation, malposition, and discoloration. This treatment modality has revealed an outstanding outcome [1], [2].

Many ceramic materials are recently optimized, regarding their mechanical and esthetic properties, to be used for ceramic laminate veneers restoring, with various thicknesses and translucencies [3].

Furthermore, ceramic adhesion systems are greatly improved to enhance their optical, physical, and mechanical properties, thus the final overall quality of the bonded ceramic restoration has been improved [4].

Computer-aided design/computer-aided manufacturing (CAD/CAM) technology plays a great role in ceramic restoration designing and manufacturing, especially ceramic laminate veneers, regarding the ease of manufacturing, time saving, and accuracy [5].
CAD/CAM technology makes it possible to set the cement space digitally using software settings. It has been reported that different settings have an impact on the final properties of the cemented ceramic restorations [6], [7].

The ability of achieving matched final ceramic laminate veneer color is a great challenge that affects the esthetic success of the treatment.

The hypothesis of this research is that the internal relief space affects the color of the ceramic laminates.

\section{Materials and Methods}

\section{Ceramic laminate veneer acrylic dentotype} preparation

Two sectional calibrating matrices were fabricated before preparation on an acrylic resin 
dentotype upper central incisor model (horizontal and vertical sections).

Ceramic laminate veneer preparation was done following the standard preparation measures, with labial preparation with average $0.5 \mathrm{~mm}$, supragingival chamfer finish line, and $2 \mathrm{~mm}$ butt joint incisal preparation. The preparation was verified using the two calibrating matrices (Figure 1).

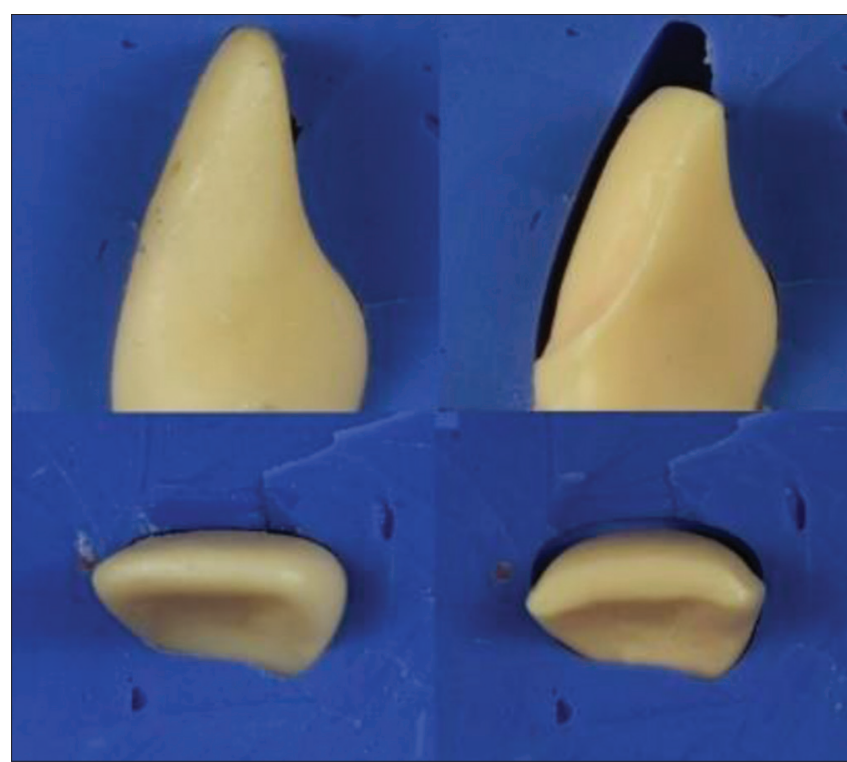

Figure 1: Preparation calibration using sectional calibrating index

The tooth was polished with a nylon bristle brush and polishing paste at $5000 \mathrm{rpm}$ in a slow speed headpiece (Figure 2).

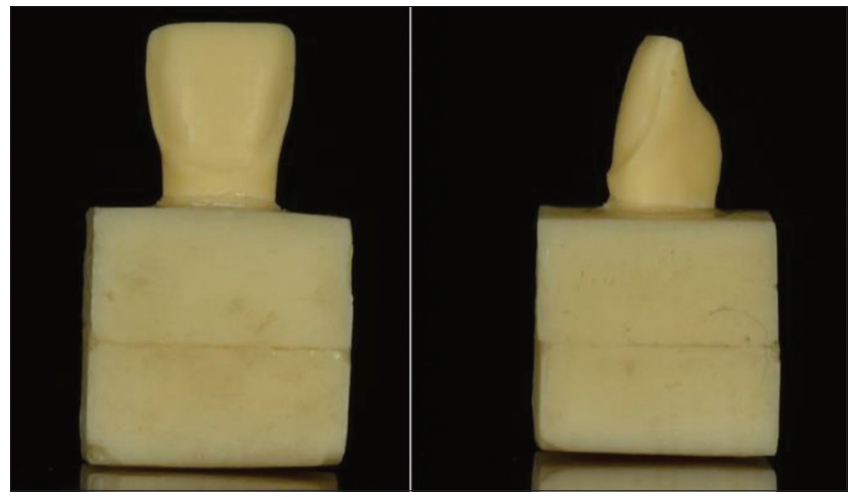

Figure 2: Resin dentotype ceramic laminate veneer preparation

\section{fabrication}

\section{Ceramic laminate veneer specimens}

The prepared upper central incisor acrylic resin dentotype was scanned with intraoral CAD/CAM optical scanner (CEREC Omnicam|Dentsply Sirona). Laminate veneer design was planned on the optically scanned preparation on CAD/CAM system software (CEREC software|Dentsply Sirona) with $0.5 \mathrm{~mm}$ thickness and $2 \mathrm{~mm}$ incisal height. The design parameters were set according to zirconia-reinforced lithium silicate (Celtra duo; Dentsply/Sirona) manufacturer parameters. The internal relief setting (IRS) parameter was adjusted to
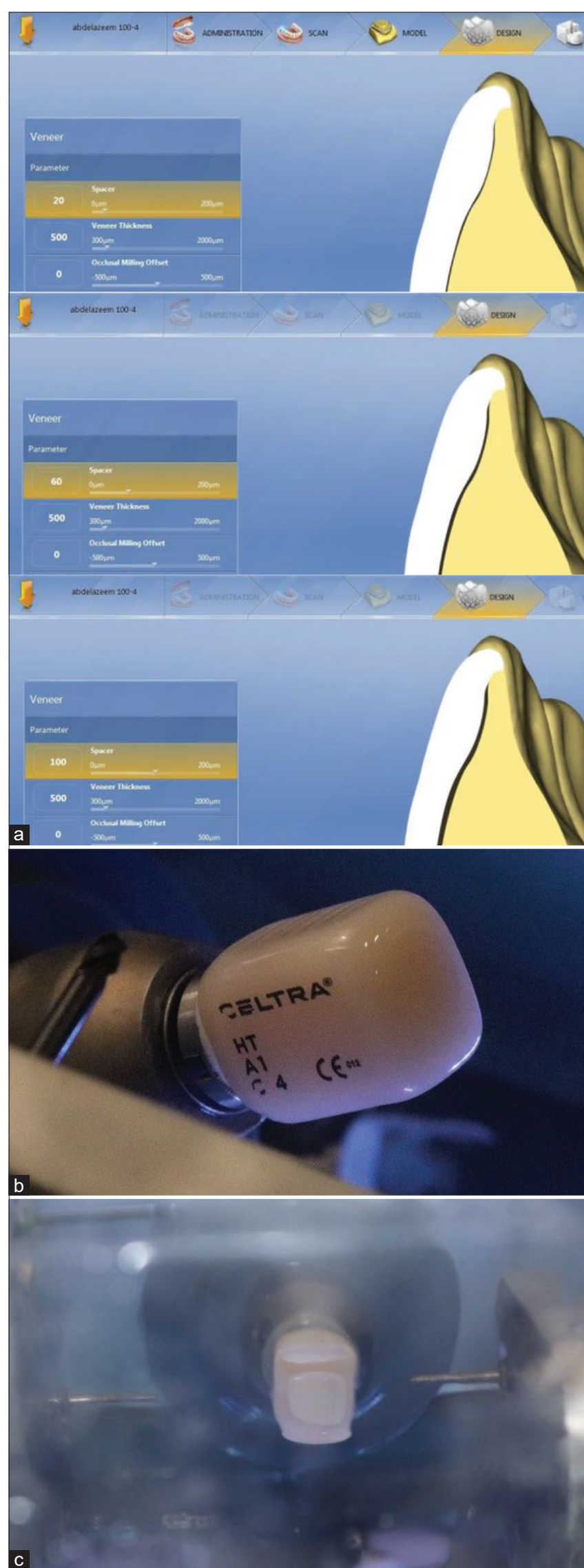

Figure 3: Internal relief space setting (a) IRS $=20 \mu \mathrm{m}$, (b) IRS $=60 \mu \mathrm{m}$, (c) IRS $=100 \mu \mathrm{m}$

$20 \mu \mathrm{m}$ (Figure 3a), then 10 ceramic laminate veneer specimens were milled from Celtra Duo blocks by Sirona 
Cerec MC XL - Dental Milling Machine: IRS20 group. The IRS parameter was adjusted to $60 \mu \mathrm{m}$ (Figure $3 \mathrm{~b}$ ), then 10 ceramic laminate veneer specimens were milled: IRS60 group. The IRS parameter was adjusted to $100 \mu \mathrm{m}$ (Figure 3c), and then, 10 ceramic laminate veneer specimens were milled: IRS100 group. Hence, a total of 30 ceramic laminate veneer specimens were milled and divided into three groups $n=10$, according to internal relief space setting parameter (Figure 4).

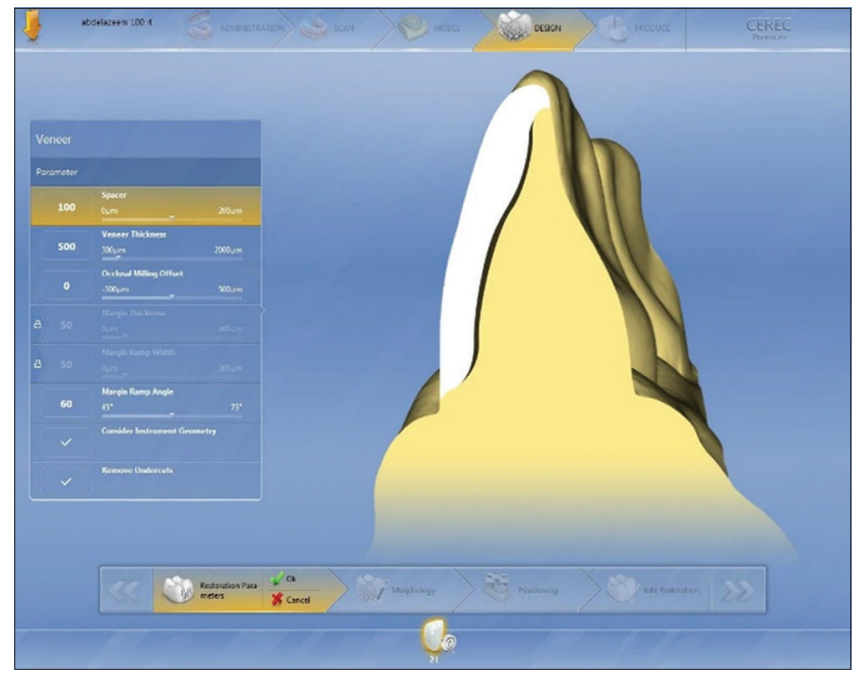

Figure 4: Ceramic laminate veneer milling

\section{Epoxy resin dies fabrication}

A cylindrical mold was fabricated to be used as a customized impression tray [8]. An impression was taken to the dentotype upper central incisor model using a polyvinyl siloxane addition silicon impression material (Hydrorise, Zhermack, Italy) (Figure 5).
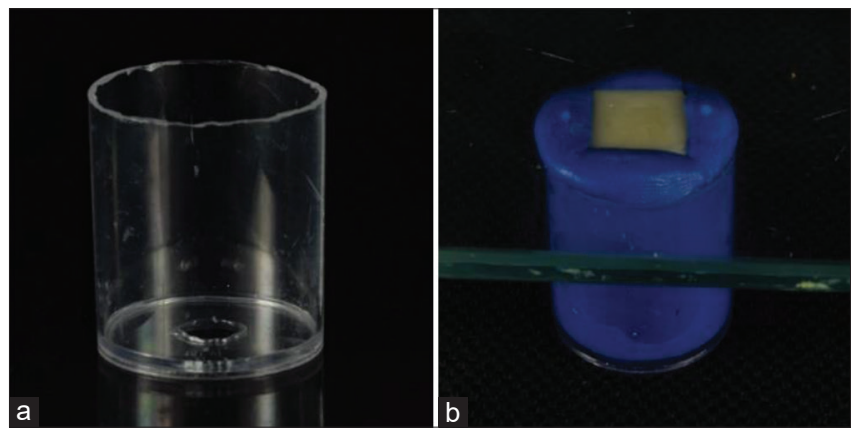

Figure 5: (a) Plastic mold, (b) dentotype tooth duplication

The impression space was poured with freshly mixed epoxy die material (Chema poxy150 3D, CMB chemicals, Egypt) [9]. The epoxy resin dies were left for $24 \mathrm{~h}$ to ensure complete setting and then separated from the silicon impression material and checked for any imperfections using magnification loupes (Figure 6). This procedure was repeated for 30 times to fabricate 30 epoxy dies with the same laminate veneer preparation. A total of 30 die specimens were randomly divided into three equal groups, $n=10$.

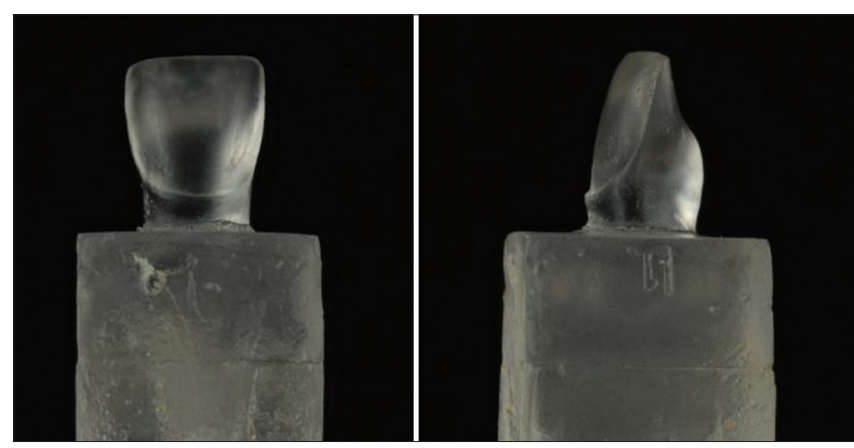

Figure 6: The duplicated epoxy die

\section{Cementation procedures}

The ceramic fitting surfaces of the ceramic laminate veneer were acid etched by hydrofluoric acid etch 5\% (for $20 \mathrm{~s}$ ) (Porcelain Etchant, BISCO, USA). The acid etch was water rinsed for $20 \mathrm{~s}$, then cleaned in ultrasonic bath for $3 \mathrm{~min}$ and dried with oil-free air stream. The silane coupling agent (Porcelain Primer, Bisco, USA) was applied to the fitting surface of the veneer and allowed to dry for $1.5 \mathrm{~min}$. A layer of universal bonding agent (all bond universal, Bisco, USA) was applied without light curing followed by gentle air thinning. The surface of the epoxy die was acid etched with $37 \%$ phosphoric acid (Prime-Dent Etchant Gel, Prime-Dent) for $30 \mathrm{~s}$ then rinsed. A layer of universal bonding agent (all bond universal, Bisco, USA) was applied without light curing followed by gentle air thinning. The adhesive resin cement (Choice 2 veneer, Bisco, USA ) shade A1 was applied on the fitting surfaces of the ceramic laminate veneers [10], [11]. The veneer was seated on the abutment tooth following its path of insertion and sustained with finger pressure by a single operator[12]. The excess cement was wiped off and the veneer was tack light cured for $3 \mathrm{~s}$ to be secured in place. A glycerin gel was applied on the restoration margins to cover the cement air inhibited layer immediately after removal of excess cement. The specimen was light cured for $20 \mathrm{~s}$ on each side using light curing unit then the margins were finished using abrasive discs for $10 \mathrm{~s}$ (Sof-Lex, 3M, ESPE, St. Paul, MN, USA) (Figure 7).
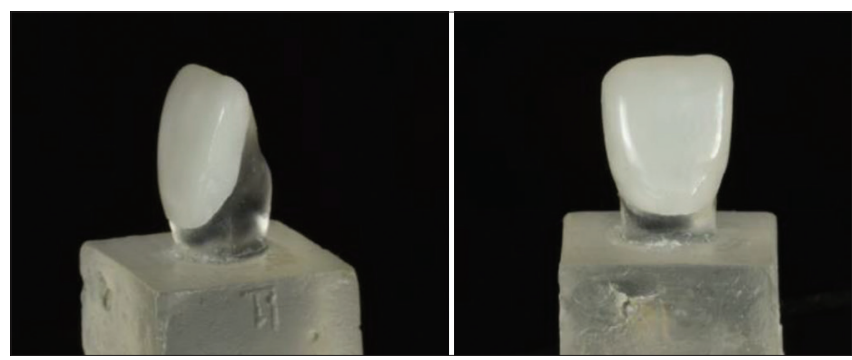

Figure 7: Cemented ceramic laminate veneer on epoxy die model

\section{Factorial design}

A total of 30 ceramic laminate veneers specimens cemented to epoxy dies were fabricated. The 30 specimens were divided into three groups; 
$\mathrm{n}=10$, according to the internal relief space value (IRS); Group 1: IRS = $20 \mu \mathrm{m}$, Group 2: IRS = $60 \mu \mathrm{m}$, and Group 3: IRS = $100 \mu \mathrm{m}$.

\section{Color parameter measuring}

The optical condition of all specimens was standardized by fixing the lightening conditions and putting over a white background. Each specimen was measured 2 times (before and after cementation).

With a spectrophotometer (Vita Easy shade, Ivoclar Vivadent AG, Schaan, Liechtenstein) using the CIELAB scale and $L^{*}, a^{*}, b^{*}$. The probe tip of the device was placed on the central part of the labial surface of the laminate veneer and the color was measured. Spectrophotometer recalibration was done after each group color data collection. The value of color difference $(\Delta \mathrm{E})$ was calculated according to the equation:

$\Delta E=\left[\left(L_{2}^{*}-L_{1}^{*}\right)^{2}+\left(a_{2}^{*}-a_{1}^{*}\right)^{2}+\left(b_{2}^{*}-b_{1}^{*}\right)^{2}\right]^{1 / 2}[13]$

$\left(L^{*}\right)$ represents lightness, $\left(a^{*}\right)$ for green-red and $\left(b^{*}\right)$ for blue, yellow.

(1) represents the color measures before cementation and (2) represents the color measure after cementation.

$\Delta \mathrm{E}<3.3$ was taken as standard clinically acceptable color difference measure [14].

The $\Delta \mathrm{E}$ of the three groups was compared to investigate the effect of the internal relief space on the color of the ceramic laminate veneers.

\section{Statistical analysis}

Normally distributed variables were compared using one-way analysis of variance (ANOVA) test. Adjustments of $p$ value were done using the Bonferroni method for multiple testing.

All $p$-values are two sided. $p \leq 0.05$ was considered statistically significant.

Data management and statistical analysis were performed using the Statistical Package for the Social Sciences version 18.

\section{Results}

The highest mean value was recorded in G100 group (1.91 \pm 0.33 ), followed by G60 group (1.83 \pm 0.09 ), with the least value recorded in $\mathrm{G} 20$ group (1.49 \pm 0.49 ). ANOVA test revealed a statistically significant difference between groups $(p=0.024)$. Bonferroni test revealed that group $\mathrm{G} 60$ was not significantly different from each of G20 and G100 groups (Table 1 and Figure 8).

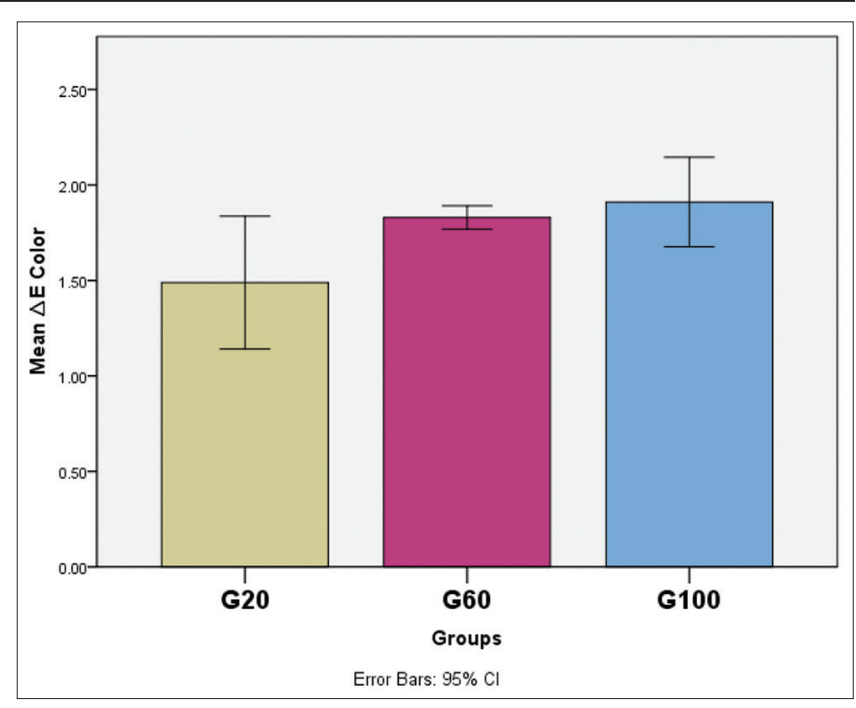

Figure 8: Bar chart illustrating mean $\Delta E$ color in different groups

Bonferroni test means sharing the same superscript letter is not significantly different.

Table 1: Descriptive statistics and comparison of $\Delta \mathrm{E}$ color in different groups (ANOVA test)

\begin{tabular}{|c|c|c|c|c|c|c|c|c|c|}
\hline \multirow[t]{2}{*}{$\begin{array}{l}\mathrm{EE} \\
\text { color }\end{array}$} & \multirow[t]{2}{*}{ Mean } & \multirow[t]{2}{*}{$\begin{array}{l}\text { Std. } \\
\text { deviation }\end{array}$} & \multirow[t]{2}{*}{$\begin{array}{l}\text { Std. } \\
\text { error }\end{array}$} & \multicolumn{2}{|c|}{$\begin{array}{l}\text { 95\% confidence } \\
\text { interval for mean }\end{array}$} & \multirow[t]{2}{*}{ Min. } & \multirow[t]{2}{*}{ Max. } & \multirow[t]{2}{*}{$\mathrm{F}$} & \multirow[t]{2}{*}{ Sig. } \\
\hline & & & & $\begin{array}{l}\text { Lower } \\
\text { bound }\end{array}$ & $\begin{array}{l}\text { Upper } \\
\text { bound }\end{array}$ & & & & \\
\hline G20 & $1.49^{b}$ & 0.49 & 0.15 & 1.14 & 1.84 & 0.87 & 2.15 & 4.283 & $0.024^{*}$ \\
\hline $\mathrm{G} 60$ & $1.83^{\mathrm{a}, \mathrm{b}}$ & 0.09 & 0.03 & 1.77 & 1.89 & 1.71 & 1.93 & & \\
\hline $\mathrm{G} 100$ & $1.91^{\mathrm{a}}$ & 0.33 & 0.10 & 1.68 & 2.15 & 1.59 & 2.61 & & \\
\hline
\end{tabular}

\section{Discussion}

Various glass-ceramic materials can be used in fabrication of ceramic laminate veneers.

Recently, a zirconia-reinforced lithium silicate glass-ceramic is introduced for dental CAD/CAM applications, as Celtra Duo and Vita Suprinity, for the fabrication of inlays, onlays, partial crowns, veneers, and anterior and posterior crowns [15], [16].

The color of the ceramic laminate veneer is considered a superior quality that affects the success of the esthetic restoring.

Many factors can affect the color of ceramic laminate veneer as the material [15], [17] and the thickness of veneering ceramic [18]. Furthermore, the resin cement composition and brand [19], [20], color [14], [21], and thickness [22] can affect the final color of the cemented ceramic laminate veneer. Hernandes et al. [14] investigated the effect of two different resin cement shades (A1 and $A 3)$ on color change, translucency parameter (TP), and chroma of low (LT) and high (HT) translucent reinforced lithium disilicate ceramic laminates. Two translucencies of a lithium disilicate glass-ceramic material (IPS e.max Press HT and LT, A2 shade, $n=5 /$ each; Ivoclar Vivadent, 
Schaan, Liechtenstein) were used in the study. Two shades of one dual-cured resin cement (Variolink II, A1and A3-shade, Ivoclar Vivadent) were applied to $1 \mathrm{~mm}$ thick ceramic discs to create thin RC layer $(100 \mu \mathrm{m}$ thick) under the ceramics. The RC was cured using light from a LED curing unit. The color change $(\Delta E)$ of ceramic discs was measured according to $\mathrm{CIEL}^{*} \mathrm{a}^{*} \mathrm{~b}^{*}$ system. $\Delta \mathrm{E}$ of 3.3 was set as the threshold of clinically unacceptable color change. There was a significant difference in $\triangle E$, TP, and chroma values for the factors ceramic translucency and cement shade $(p<0.0001)$ with power higher than $90 \%$, but no statistically significant interaction between factors was detected $(p>0.05)$ for any of the evaluated parameters. The $\Delta E$ value obtained for HT ceramic was significantly higher than that of LT ceramic, regardless of $\mathrm{RC}$ shade. Furthermore, the $\Delta \mathrm{E}$ was significantly higher when $A 3$ shade $R C$ was used than when $A 1$ shade cement was placed under the ceramics, regardless of ceramic translucency. Hence, they concluded that the translucency of the ceramic material as well as the resin cement shade can affect the final color of the ceramic laminate veneer. Clearance is needed between a fixed restoration and the prepared tooth fitting surface to provide space for the luting agent. Methods such as venting, axial grooves, and provision of axial cement space have been used to reduce the hydraulic pressure between the cement and cast restoration and, therefore, improve seating, decrease seating time, and allow the escape of excess cement [23]. This space can be provided by manual die spacer coats application [23]. CAD technology provides the ability to virtually design restorations and program the die spacer thickness [24], [25].

Ravi et al. [22] made a scoping review to analyze the shade and thickness of resin cement effectiveness on the final color of the veneer restoration. The search resulted in three studies reporting the effect of resin cement shade on porcelain. Various resin cement systems with similar shade showed different color parameters and changes in final translucency. None of the studies compared the thickness parameter of resin cement on the final color of restoration. Hence, they claimed that the esthetic outcome of veneer restorations is reflected by the shade of resin luting cements, considering the mean color difference within various cement systems. There is a crucial need for further research to investigate the effect of cement thickness on final color of ceramic laminate veneers and a standardized resin cement shade classification.

Zaghloul and Mohsen [24] evaluated the optical behavior of three different CAD/CAM veneer materials with different internal relief spaces and different cement shades. Sixty samples were constructed and classified according to the type of materials into three main groups (I) IPS e.max CAD MT, (II) VITA Vitablocs Mark II, and (III) Vita Suprinity $(n=20)$. Each group was subdivided into two subgroups $(n=10)$ according to the internal relief space $(100 \mu \mathrm{m}$ and $30 \mu \mathrm{m})$. Each subgroup was further subdivided into six classes according to the four types of trial cements used. The color test was done using reflectance spectrophotometer device (Vita Easy shade V). The color was measured in different combinations of laminate veneer material, internal relief space, and trial insertion paste color on composite resin abutment A3. The luminous transmittance exhibited a statistically significant dependence on different ceramic restorations with a cad cam veneers in different internal relief spaces and different cement shade combinations $(p<0.05)$. Hence, the conclusion was that the underlying color of the tested trial insertion pastes caused color change $(\Delta E>3.7)$ for all ceramic material used in this study. However, there was no significant difference between the effect of the two shades of internal relief spaces (30 and $100 \mu \mathrm{m}$ ) with different shades of the trial cement pastes on translucency of each ceramic material.

The aim of this study is to evaluate the effect of different internal relief space setting on the color of ceramic laminate veneer fabricated from CAD/CAM zirconia-reinforced lithium silicate glass-ceramic (Celtra Duo blocks; Dentsply/Sirona).

The internal relief space setting was controlled during designing of the laminate veneer by Cerec software (Dentsply/Sirona).

Three internal relief space settings, 20,60 , and $100 \mu \mathrm{m}$, were investigated according to the average clinically applied measures [26], [27].

The tests revealed that all the groups showed color change. The threshold of color difference below 3.3 is considered clinically acceptable [14], [28].

In this study, the color changes were below this threshold. The differences caused by cements could be detected by a human eye but could still be clinically acceptable.

The highest value was in $\mathrm{G} 100$ with a significant difference from $\mathrm{G} 20$ that reflects the significant impact of changing the internal relief space setting on the color of the ceramic laminate veneer.

\section{Conclusion}

It can be concluded that the digital internal relief space setting can affect the color of ceramic laminate veneer. Although some of these differences may not be clinically noticeable with the difference of the digital IRS, it should be taken in consideration during fabrication of ceramic laminate veneer.

The limitation of the study was the in vitro investigation of the color change on epoxy models. Further in vivo studies may be needed. 


\section{References}

1. Granell-Ruiz M, Fons-Font A, Labaig-Rueda C, MartínezGonzález A, Rodríguez JL, Ruiz MF. A clinical longitudinal study 323 porcelain laminate veneers. Period of study from 3 to 11 years. Med Oral Patol Oral Cir Bucal. 2010;15:e531-7. https:// doi.org/10.4317/medoral.15.e531

PMid:20038893

2. Fradeani $M$, Redemagni $M$, Corrado $M$. Porcelain laminate veneers: 6-to 12-year clinical evaluation-a retrospective study. Int J Periodontics Restorative Dent. 2005;25(1):9-17.

PMid: 15736774

3. Font AF, Ruiz F, Ruíz MG, Rueda CL, González AM. Choice of ceramic for use in treatments with porcelain laminate veneers. Med Oral Patol Oral Cir Bucal. 2006;11(3):E297-302. https://doi. org/10.4317/medoral.19097

PMid:16648772

4. Perroni AP, Kaizer MR, Bona AD, Moraes RR, Boscato N Influence of light-cured luting agents and associated factors on the color of ceramic laminate veneers: A systematic review of in vitro studies. Dent Mater. 2018;34(11):1610-24. https://doi. org/10.1016/j.dental.2018.08.298

PMid:30213524

5. Nejatidanesh F, Savabi G, Amjadi M, Abbasi M, Savabi O. Five year clinical outcomes and survival of chairside CAD/CAM ceramic laminate veneers-a retrospective study. J Prosthodont Res. 2018;62(4):462-7. https://doi.org/10.1016/j.jpor.2018.05.004 PMid:29936052

6. Iwai T, Komine F, Kobayashi K, Saito A, Matsumura H. Influence of convergence angle and cement space on adaptation of zirconium dioxide ceramic copings. Acta Odontol Scand. 2008;66(4):214-8. https://doi.org/10.1080/00016350802139833 PMid:18607834

7. Alghazzawi TF, Liu PR, Essig ME. The effect of the computer luting space setting on the fracture strength of CAD/CAM generated ceramic copings. Smile Dent J. 2014;9(3):14-8. https://doi.org/10.12816/0010805

8. Badran N, Kader SA, Alabbassy F. Effect of incisal porcelain veneering thickness on the fracture resistance of CAD/ CAM zirconia all-ceramic anterior crowns. Int J Dent. 2019;2019:6548519. https://doi.org/10.1155/2019/6548519 PMid:31534456

9. Pallis K, Griggs JA, Woody RD, Guillen GE, Miller AW. Fracture resistance of three all-ceramic restorative systems for posterior applications. J Prosthet Dent. 2004;91(6):561-9. https://doi. org/10.1016/j.prosdent.2004.03.001 PMid:15211299

10. El Sayed SM, Basheer RR, Bahgat SF. Color stability and fracture resistance of laminate veneers using different restorative materials and techniques. Egypt Dent J. 2016;62:1-15.

11. Mohammed BK. Evalution of Fracture Resistance of Cerasmart and Lithium Disilcate Ceramic Veneers with Different Incisal Preparation Designs. 2019. https://doi.org/10.12688/f1000research.20103.1

12. Chai SY, Bennani V, Aarts JM, Lyons K, Lowe BJ. Effect of incisal preparation design on load-to-failure of ceramic veneers. $J$ Esthet Restor Dent. 2020;32(4):424-32. https://doi.org/10.1111/jerd.12584 PMid:32270920

13. Hamza TA, Al-Baili MA, Abdel-Aziz MH. Effect of artificially accelerated aging on margin fit and color stability of laminate veneers. Stomatol Dis Sci. 2018;2:1. https://doi. org/10.20517/2573-0002.2017.09

14. Hernandes DK, Arrais CA, Cesar PF, Rodrigues JA. Influence of resin cement shade on the color and translucency of ceramic veneers. J Appl Oral Sci. 2016;24(4):391-6. https://doi. org/10.1590/1678-775720150550

PMid:27556211

15. Sen N, Us YO. Mechanical and optical properties of monolithic CAD-CAM restorative materials. J Prosthet Dent. 2018;119(4):5939. https://doi.org/10.1016/j.prosdent.2017.06.012 PMid:28781072

16. Mohamed IS. Evaluation of Marginal Integrity of Laminate Veneers Constructed from Two Different Ceramic Materials, CU Theses; 2020.

17. Baldissara P, Wandscher VF, Marchionatti AM, Parisi C Monaco C, Ciocca L. Translucency of IPS e. max and cubic zirconia monolithic crowns. J Prosthet Dent. 2018;120(2):26975. https://doi.org/10.1016/j.prosdent.2017.09.007 PMid:29475752

18. DouglasRD,PrzybylskaM.Predicting porcelainthicknessrequired for dental shade matches. J Prosthet Dent. 1999;82(2):143-9. https://doi.org/10.1016/s0022-3913(99)70147-2 PMid:10424975

19. Turgut S, Bagis B. Effect of resin cement and ceramic thickness on final color of laminate veneers: An in vitro study. J Prosthet Dent. 2013;109(3):179-86. https://doi.org/10.1016/ s0022-3913(13)60039-6 PMid:23522367

20. Hoorizad M, Valizadeh S, Heshmat H, Tabatabaei SF, Shakeri TJ. Influence of resin cement on color stability of ceramic veneers: In vitro study. Biomater Investig Dent. 2021;8(1):11-7. https:// doi.org/10.1080/26415275.2020.1855077 PMid:33554126

21. Alqahtani MQ, Aljurais RM, Alshaafi MM. The effects of different shades of resin luting cement on the color of ceramic veneers. Dent Mater J. 2012;31(3):354-61. https://doi.org/10.4012/dmj.2011-268 PMid:22673474

22. Ravi A, Raj RS, Babu AS, Keepanasseril A, Mathew A. Effectiveness of shade and thickness of resin cement on the final colour of the porcelain laminate veneer: A scoping review. J Clin Diagn Res. 2019;13(2):ZE01-5. https://doi.org/10.7860/ jcdr/2019/38481.12576

23. Cho SH, Chang WG, Lim BS, Lee YK. Effect of die spacer thickness on shear bond strength of porcelain laminate veneers. J Prosthet Dent. 2006;95(3):201-8. https://doi.org/10.1016/j. prosdent.2005.12.011

PMid:16543017

24. Zaghloul $\mathrm{KI}$, Mohsen CA. Translucency of cad/cam veneers using different internal relief spaces and luting cement shades. Indian J Public Health Res Dev. 2020;11(6):1316-22. https://doi. org/10.37506/ijphrd.v11i6.9985

25. Hmaidouch R, Neumann P, Mueller WD. Influence of preparation form, luting space setting and cement type on the marginal and internal fit of CAD/CAM crown copings. Int J Comput Dent. 2011;14(3):219-26

PMid:22141231

26. Liu HL, Lin CL, Sun MT, Chang YH. Numerical investigation of macro-and micro-mechanics of a ceramic veneer bonded with various cement thicknesses using the typical and submodeling finite element approaches. J Dent. 2009;37(2):141-8. https://doi. org/10.1016/j.jdent.2008.10.009

PMid:19084316

267. Sabarinathan S, Sreelal T, Rajambigai A, Anusuya S. Evaluation of influence of die spacer thickness on the shear bond strength of porcelain laminate veneers: An in vitro study. Indian J Stomatol. 2016;7(2):42. https://doi.org/10.1016/s0084-3717(08)70342-8

28. Paris S, Schwendicke F, Keltsch J, Dörfer C, Meyer-Lueckel H. Masking of white spots lesions by resin infiltration in vitro. J Dent. 2013;41 Suppl 5:e28-34. https://doi.org/10.1016/j.jdent.2013.04.003 PMid:23583919 